Published in final edited form as:

Chem Res Toxicol. 2016 February 15; 29(2): 142-149. doi:10.1021/acs.chemrestox.5b00308.

\title{
Reactivity of Biliatresone, a Natural Biliary Toxin, with Glutathione, Histamine, and Amino Acids
}

\author{
Kyung A. Koo* ${ }^{\star} \dagger$, Orith Waisbourd-Zinman ${ }^{\ddagger}$, Rebecca G. Wells ${ }^{\S, \|}$, Michael Pack ${ }^{\S, \perp}$, and \\ John R. Porter ${ }^{*}, \dagger$ \\ tDepartment of Biological Sciences, University of the Sciences, Philadelphia, Pennsylvania \\ 19104, United States \\ ¥Division of Pediatric Gastroenterology, Hepatology, and Nutrition, The Children's Hospital of \\ Philadelphia, Philadelphia, Pennsylvania 19104, United States \\ §Department of Medicine, University of Pennsylvania, Philadelphia, Pennsylvania 19104, United \\ States \\ "Department of Pathology, University of Pennsylvania, Philadelphia, Pennsylvania 19104, United \\ States \\ ${ }^{\perp}$ Department of Cell Biology and Laboratory Medicine, Perelman School of Medicine, University \\ of Pennsylvania, Philadelphia, Pennsylvania 19104, United States
}

\section{Abstract}

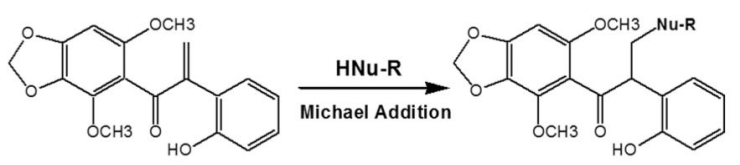

HNu-R: thiol and free imidazole

- GSH, Cysteine, NAC, Histidine, Histamine

In our previous work, we identified a natural toxin, biliatresone, from Dysphania glomulifera and D. littoralis, endemic plants associated with outbreaks of biliary atresia in Australian neonatal livestock. Biliatresone is a very rare isoflavonoid with an $\alpha$-methylene ketone between two phenyls, 1,2-diaryl-2-propenone, along with methylenedioxy, dimethoxyl, and hydroxyl functional groups, that causes extrahepatic biliary toxicity in zebrafish. The toxic core of biliatresone is a methylene in the $a$-position relative to the ketone of 1,2-diaryl-2-propenone that serves as an electrophilic Michael acceptor. The $\alpha$-methylene of biliatresone spontaneously conjugated with

*Corresponding Authors: (K.A.K.) k.koo@usciences.edu. (J.R.P.) j.porter@usciences.edu..

Publisher's Disclaimer: This document is the Accepted Manuscript version of a Published Work that appeared in final form in Chemical Research in Toxicology, copyright $\odot 2016$ American Chemical Society after peer review and technical editing by the publisher. To access the final edited and published work see http://pubsdc3.acs.org/articlesonrequest/AOR-

tM4ZSAVfXWJEkPTgWNaP.

\section{ASSOCIATED CONTENT}

Supporting Information

The Supporting Information is available free of charge on the ACS Publications website at DOI: 10.1021/acs.chemrestox.5b00308. NMR, HPLC, and LC-MS data for analysis of the reactivity of biliatresone (PDF)

The authors declare no competing financial interest. 
water and methanol $(\mathrm{MeOH})$, respectively, via Michael addition in a reverse phase highperformance liquid chromatography (RP-HPLC) analysis. We here report the reactivity of biliatresone toward glutathione (GSH), several amino acids, and other thiol- or imidazolecontaining biomolecules. LC-MS and HPLC analysis of the conjugation reaction showed the reactivity of biliatresone to be in the order histidine $>N$-acetyl-D-cysteine (D-NAC) $=N$-acetyl-Lcysteine $($ L-NAC) $>$ histamine $>$ glutathione $\geq$ cysteine $\gg$ glycine $>$ glutamate $>$ phenylalanine, while serine and adenine had no reactivity due to intramolecular hydrogen bonding in the protic solvents. The reactivity of ethyl vinyl ketone (EVK, 1-penten-3-one), an example of a highly reactive $a, \beta$-unsaturated ketone, toward GSH gave a 6.7 -fold lower reaction rate constant than that of biliatresone. The reaction rate constant of synthetic 1,2-diaryl-2-propen-1-one (DP), a core structure of the toxic molecule, was 10-fold and 1.5-fold weaker in potency compared to the reaction rate constants of biliatresone and EVK, respectively. These results demostrated that the methylenedioxy, dimethoxyl, and hydroxyl functional groups of biliatresone contribute to the stronger reactivity of the Michael acceptor $a$-methylene ketone toward nucleophiles compared to that of DP and EVK.

\section{INTRODUCTION}

Biliatresone was identified from Dysphania glomulifera and D. littoralis as a selective extrahepatic biliary toxin leading to biliary dysfunction in zebrafish in vivo and loss of cilia and cell polarity in in vitro cultures of neonatal mouse extrahepatic cholangiocytes. ${ }^{1}$ Four outbreaks of biliary atresia have been reported in newborn lambs born to pregnant ewes grazed in atypical pastures where Dysphania ssp. plants were the predominant flora; this suggested the cause of biliary atresia to be exposure to a toxin in utero. ${ }^{1} \mathrm{We}$ investigated the causative toxin and identified biliatresone (Figure 1), an isoflavonoid in the very rare 1,2diaryl-2-propenone class. ${ }^{1,2}$ Similar compounds have been reported as bacterial metabolites of the human microflora and the fungal degradation of lignin. 3,4

Biliatresone spontaneously reacts and conjugates with water and $\mathrm{MeOH}$ to give solvent adducts, which we analyzed by LC-MS. ${ }^{2}$ On the basis of the HMBC analysis data of the $\mathrm{MeOH}$ adduct, the reactive Michael acceptor is the methylene in the $\alpha$-position relative to the ketone; an $\alpha$-methylene ketone is well-known as a highly reactive moiety. ${ }^{5}$ Spontaneous nucleophilic attack of $\mathrm{MeOH}$ to the $\alpha$-methylene causes oxidative cleavage and readily forms the $\mathrm{MeOH}$ adduct. We tested this hypothesis through study of the reactivity and toxicity of synthetic 1,2-diaryl-2-propen-1-one (DP) without the methylenedioxy, dimethoxyl, and hydroxyl functional groups (Figure 1). Biliatresone specifically targets the extrahepatic biliary system. ${ }^{1}$ In contrast, the synthetic DP was generally toxic to zebrafish larva in vivo, but it conjugated with $\mathrm{MeOH}$ in the same manner as biliatresone. ${ }^{2}$ The methylenedioxy, dimethoxyl, and hydroxyl side groups on the two phenyls may provide the specificity and higher toxicity.

In this study, we investigated the reactivity of biliatresone toward endogenous nucleophiles and biomolecules in a conjugation assay. Analysis of conjugation with GSH and amino acids with HPLC, LC-MS, and NMR is a common method to characterize chemical reactivity and identify bioactivity. ${ }^{6-8}$ We used a slightly modified conjugation assay under 
nonenzymatic and noncatalytic conditions and analyzed the reactants. Analysis of the reactivity of ethyl vinyl ketone (EVK, 1-penten-3-one), which is well-known as a highly reactive electrophile, toward GSH was compared to that of biliatresone and DP in our conjugation assay. ${ }^{5,9,10}$ The comparison of the EVK reactivity to those of DP and biliatresone provides an evaluation of our study compared to the previous kinetic assays of GSH reactivity. ${ }^{9,10}$ This design provides valuable indirect evidence for the interaction between the plant toxin and various endogenous biological substances. Through the study of the chemical reactivity of biliatresone with GSH, various amino acids (cysteine, glycine, glutamate, histidine, phenylalanine, and serine), a DNA base (adenine), derivatives of cysteine (D-NAC and L-NAC), and a imidazole moiety (histamine), we can infer toxic mechanisms or likely targets leading to the biliary toxicity that we have observed in vivo (Figure 1). We here report the characterization of the reactivity of the natural toxin biliatresone and the synthetic DP.

\section{MATERIALS AND METHODS}

\section{General Experimental Procedures}

HPLC-grade solvents ( $\mathrm{MeOH}, \mathrm{ACN}, \mathrm{EtOH}$, and water), amino acids (DL-cysteine, Lglutamate, L-glycine, L-histidine, L-phenylalanine, and DL-serine), N-acetyl-L-cysteine (LNAC), adenine, histamine, and ethyl vinyl ketone (EVK; 1-penten-3-one) purchased from Sigma-Aldrich (St. Louis, MO, USA) were used in all processes, including HPLC and LCMS. N-Acetyl-D-cysteine (D-NAC; catalog \#117600) was custom synthesized by Princeton BioMolecular Research (Monmouth Junction, NJ, USA). HPLC was performed at room temperature $\left(25^{\circ} \mathrm{C}\right)$ in an Agilent 1100 series system (Santa Clara, CA, USA) equipped with a vacuum degasser, quaternary pump, thermostatically controlled column compartment, autosampler, and diode array detector (DAD). LC-MS (ESI, positive mode, $\mathrm{m} / \mathrm{z}$ ) spectra were collected on a Shimadzu LCMS-2010EV system (Kyoto, Japan) equipped with a vacuum degasser, quaternary pump, thermostatically controlled column compartment, autosampler, and UV detector. The NMR lock solvent $\left(\mathrm{CD}_{3} \mathrm{OD}\right)$ was purchased from Cambridge Isotope Laboratories (Andover, MA, USA). The chemical structure of the GSH conjugate of biliatresone was elucidated by ${ }^{1} \mathrm{H}$ NMR, ${ }^{13} \mathrm{C}$ NMR, and 2D NMR (HSQC and HMBC) techniques. The NMR spectra were acquired on a Bruker AVANCE 400II spectrometer with ${ }^{1} \mathrm{H}$ and ${ }^{13} \mathrm{C}$ frequencies of 400 and $100 \mathrm{MHz}$, respectively. Chemical shifts were in ppm and relative to tetramethylsilane; coupling constants $(J)$ were reported in $\mathrm{Hz}$.

\section{HPLC and LC-MS Analysis}

The spectra were obtained with analytical columns (Waters Symmetry C18 and Zorbax C-18, $250 \times 4.6 \mathrm{~mm}, 5 \mu \mathrm{m}$ ) with UV detection at $254 \mathrm{~nm}$ for the GSH-biliatresone adduct and at $206 \mathrm{~nm}$ for all other adducts in the time-dependence and single time experiments. The solvent systems consisted of isocratic water/MeOH/ACN (4:3:3, v/v/v) for a MeOH-based solvent and water/EtOH/ACN (4:3:3, v/v/v) for an EtOH-based solvent. Flow rates were 0.2, 0.3 , or $0.5 \mathrm{~mL} / \mathrm{min}$. The temperature of the column compartment was controlled at $25{ }^{\circ} \mathrm{C}$. 


\section{GSH Adduct of Biliatresone}

To determine the reactivity of GSH toward biliatresone, $10 \mathrm{mM} \mathrm{GSH}$ and a mixture of the $\mathrm{MeOH}$ adduct and biliatresone (approximately $3 \mathrm{mM} ; 1 \mathrm{mg} / \mathrm{mL}$ ) in $\mathrm{MeOH} /$ water (1:1) were incubated for $0,5,10,20,40$, and $60 \mathrm{~min}$ for a short-term reaction and $1.5,9$, and $18 \mathrm{~h}$ for a long-term reaction. It should be noted that formation of the $\mathrm{MeOH}$ adduct of biliatresone is unavoidable in solvent systems that contain $\mathrm{MeOH}$, and the $\mathrm{MeOH}$ adduct cannot be purified without conversion to a mixture of the $\mathrm{MeOH}$ adduct and biliatresone. The products were analyzed by HPLC and LC-MS with the MeOH-based solvent system [water/ $\mathrm{MeOH} / \mathrm{ACN}$ (4:3:3), $0.2 \mathrm{~mL} / \mathrm{min}, 5 \mu \mathrm{L}$ injection]. The LC chromatograms were obtained at $254 \mathrm{~nm}$, with the aim to maximize the signal intensity of the GSH adduct formed with biliatresone and to reduce the signal strength of the free GSH. For NMR measurements, GSH (10 mM) was incubated with biliatresone (approximately $3 \mathrm{mM} ; 1 \mathrm{mg} / \mathrm{mL}$ ) in $200 \mu \mathrm{L}$ of $\mathrm{MeOH} /$ water $(1: 1)$ for $18 \mathrm{~h}$ at room temperature; the reaction containing the GSH adduct was prepared in $\mathrm{CD}_{3} \mathrm{OD}$ NMR lock solvent after taking the reaction mixture to dryness. The structure of the GSH adduct of biliatresone was determined by 1D- and 2D-NMR analyses.

\section{Cysteine Adduct of Biliatresone}

To follow the formation of the cysteine adduct, the conjugation reaction was performed with the same experimental design as that above with $10 \mathrm{mM}$ cysteine and the mixture of the $\mathrm{MeOH}$ adduct and biliatresone (approximately $3 \mathrm{mM}$ ). The LC chromatogram was monitored at $206 \mathrm{~nm}$. The time-dependent reaction of Figure 3B was followed by mixing the cysteine with biliatresone that was purified in the EtOH-based solvent to remove the interference of the $\mathrm{MeOH}$ conjugation. The reaction was started by the addition of cysteine to the $10 \mathrm{mM}$ final concentration in EtOH/water (1:1, v/v; total volume of $200 \mu \mathrm{L})$. The reaction was monitored at $206 \mathrm{~nm}$, and MS analyses were performed at $1 \mathrm{~h}$ intervals for $18 \mathrm{~h}$ with the EtOH-based solvent system [water/EtOH/ACN (4:3:3, v/v/v), $0.5 \mathrm{~mL} / \mathrm{min}, 5 \mu \mathrm{L}$ injection].

\section{Amino Acid, D-NAC, L-NAC, Adenine, and Histamine Adducts of Biliatresone}

The amino acids histidine, glutamate, glycine, phenylalanine, and serine and the molecules D-NAC, L-NAC, adenine, and histamine, each at a final concentration of $10 \mathrm{mM}$, were similarly incubated with the mixture of the $\mathrm{MeOH}$ adduct and biliatresone (approximately 3 $\mathrm{mM} ; 1 \mathrm{mg} / \mathrm{mL}$ ) in $200 \mu \mathrm{L}$ of $\mathrm{MeOH} /$ water (1:1) for $18 \mathrm{~h}$ under the same conditions as those for the study of the GSH conjugation. The reaction mixtures were analyzed by LC-MS [water/MeOH/ACN (4:3:3, v/v/v), 0.2, 0.3, or $0.5 \mathrm{~mL} / \mathrm{min}, 206 \mathrm{~nm}, 5 \mu \mathrm{L}$ injection]. DNAC, L-NAC, or histamine and purified biliatresone ( $2 \mathrm{mM}$ or $3 \mathrm{mM})$ in $200 \mu \mathrm{L}$ of $\mathrm{MeOH} /$ water $(1: 1)$ were incubated for the times indicated in the figures. The reaction mixtures were analyzed by HPLC [water/MeOH/ACN (4:3:3, v/v/v), $0.5 \mathrm{~mL} / \mathrm{min}, 206 \mathrm{~nm}, 5 \mu \mathrm{L}$ injection]. D-NAC and L-NAC were studied to determine whether there was any stereoisomeric effect on conjugation since the two isomers differ dramatically in their biological effects.

\section{GSH Adduct of the Synthetic 1,2-Diaryl-2-propen-1-one}

1,2-Diaryl-2-propen-1-one (DP) was obtained by synthesis during our previous work. ${ }^{2} \mathrm{GSH}$ $(10 \mathrm{mM})$ and DP (approximately $4.8 \mathrm{mM} ; 1 \mathrm{mg} / \mathrm{mL})$ in $\mathrm{MeOH} /$ water (1:1) were incubated 
for $18 \mathrm{~h}$ in a time-dependent reaction. The reaction mixtures were analyzed by HPLC [water/MeOH/ACN (4:3:3, v/v/v), $0.5 \mathrm{~mL} / \mathrm{min}, 206 \mathrm{~nm}, 5 \mu \mathrm{L}$ injection] at 0, 15, 30, and 60 min, and 17 and $18 \mathrm{~h}$.

\section{GSH Adduct of Ethyl Vinyl Ketone (EVK; 1-Penten-3-one)}

GSH $(10 \mathrm{mM})$ and EVK $(3 \mathrm{mM})$ in $\mathrm{MeOH} /$ water (1:1) were prepared and incubated for $12 \mathrm{~h}$ in a time-dependent reaction. The reaction mixtures were analyzed by HPLC [water/ $\mathrm{MeOH} / \mathrm{ACN}(4: 3: 3, \mathrm{v} / \mathrm{v} / \mathrm{v}), 0.3 \mathrm{~mL} / \mathrm{min}, 206 \mathrm{~nm}, 5 \mu \mathrm{L}$ injection] at $1 \mathrm{~h}$ intervals.

\section{Reaction of GSH with Biliatresone, DP, and EVK in a Second-Order Kinetic Analysis}

The second-order reaction rate constants $(\mathrm{k})$ were investigated between GSH $(10 \mathrm{mM})$ and the reactants biliatresone $(0.5 \mathrm{mM}), \mathrm{DP}(0.5 \mathrm{mM})$, and EVK $(0.5 \mathrm{mM})$. Reactions were carried out in $\mathrm{MeOH} /$ water (1:1) and analyzed by HPLC [Zorbax C-18 $(250 \times 4.6 \mathrm{~mm}, 5$ $\mu \mathrm{m})$, water/MeOH/ACN (4:3:3, v/v/v), $0.3 \mathrm{~mL} / \mathrm{min}\left(0.5 \mathrm{~mL} / \mathrm{min}\right.$ for DP), $206 \mathrm{~nm}, 25^{\circ} \mathrm{C}, 5$ $\mu \mathrm{L}$ injection] and followed in a time-dependent manner. The second-order rate constant expression of the reactants A and GSH is generally described by the following equation:

$$
\text { rate }=k[\mathrm{~A}][G S H]
$$

The initial concentrations of reactants $[\mathrm{A}]_{0}$ and $[\mathrm{GSH}]_{0}$ are not equal. For a given time $t, X$ is the change in the concentration of each reactant $[\mathrm{A}]_{\mathrm{t}}$ and $[\mathrm{GSH}]_{\mathrm{t}}$.

$$
[\mathrm{A}]_{\mathrm{t}}=[\mathrm{A}]_{0}-X \text { and }[G S H]_{\mathrm{t}}=[G S H]_{0}-X
$$

Then, the rate equation can be expressed as

$$
\mathrm{d} X / \mathrm{d} t=k\left([\mathrm{~A}]_{0}-X\right)\left([\mathrm{B}]_{0}-X\right)
$$

Integration of this equation and rearranging gives the linearized rate equation.

$$
\ln \left([\mathrm{A}]_{\mathrm{t}} /[G S H]_{\mathrm{t}}\right)=k\left([\mathrm{~A}]_{0}-[G S H]_{0}\right) t+\ln \left([\mathrm{A}]_{0} /[\mathrm{B}]_{0}\right)
$$

To determine the rate constants, least-squares plots of $\ln \left([\mathrm{A}]_{\mathrm{t}} /[\mathrm{GSH}]_{\mathrm{t}}\right)$ vs $t$ were calculated (Figure S13, Supporting Information). The reaction rate constant $k$ was determined by division of the slope by $[\mathrm{A}]_{0}-[\mathrm{GSH}]_{0}$.

\section{RESULTS}

The reactivity of biliatresone toward GSH was tested and analyzed by HPLC and LC-MS. In the initial test, HPLC analysis of the reaction of biliatresone and GSH for $18 \mathrm{~h}$ at room temperature $\left(\mathrm{ca} .25^{\circ} \mathrm{C}\right)$ in a water/MeOH $(1: 1, \mathrm{v} / \mathrm{v})$ solvent showed a new peak $\left(t_{\mathrm{R}} 14.1\right.$ $\mathrm{min}$ ), corresponding to a GSH adduct of biliatresone (Figure S1). As the new peak increased in size, the biliatresone peak $\left(t_{\mathrm{R}} 36.0 \mathrm{~min}\right)$ decreased. In a time-course reaction experiment of a mixture of biliatresone and its $\mathrm{MeOH}$ adduct with $\mathrm{GSH}$, the biliatresone peak 
decreased, and the new GSH adduct peak appeared, but there was no change in the $\mathrm{MeOH}$ adduct peak within $40 \mathrm{~min}$ (Figure 2A). Conjugation of GSH and biliatresone was complete by $40 \mathrm{~min}$ with a reaction rate of $\sim 0.754 \times 10^{-6} \mathrm{~mol} \mathrm{~s}^{-1}$ (Table 1). In the LC-MS analysis, the molecular ion of the new peak $\left(\mathrm{m} / z 636[\mathrm{M}+\mathrm{H}]^{+}\right)$was consistent with GSH (MW 307) plus biliatresone (MW 328) (Figure S1B). The ${ }^{1} \mathrm{H}$ NMR spectrum of the GSH adduct of biliatresone showed an absence of the olefinic protons of the $\alpha$-methylene $\left(3^{\prime}-\mathrm{H}\right)$ of biliatresone, and the HMBC spectrum showed a five bond, long-range correlation between the carbonyl carbon of biliatresone and the ethyl proton of the cysteine residue in the GSH tripeptide (Figures 3A, S2, and S3). The 2D NMR HMBC experiment, shows long-range correlation signals for ${ }^{13} \mathrm{C}$ and ${ }^{1} \mathrm{H}$ spin pairs ranging from one to five bonds. The five bond correlations are weak in the spectrum but are particularly apparent in conjugated molecules. ${ }^{11} \mathrm{GSH}$ and biliatresone spontaneously formed a thiol conjugation generated by oxidative cleavage of the $\alpha$-methylene, an example of a Michael addition reaction. In a longterm $18 \mathrm{~h}$ reaction between biliatresone and $\mathrm{GSH}$, there was a slow depletion of the $\mathrm{MeOH}$ adduct of biliatresone (Figure 2B and $\mathrm{C}$ ). As we have shown previously, the $\mathrm{MeOH}$ addition to biliatresone is reversible, and the $\mathrm{MeOH}$ adduct also exhibits a toxicity similar to that of biliatresone in the zebrafish assay. ${ }^{2}$ Depletion of the $\mathrm{MeOH}$ adduct peak over a long period again demonstrates this reversibility.

We determined the reactivity of biliatresone with cysteine alone with the same experimental design as that used for GSH. In this analysis of the biliatresone, adduct, and cysteine mixture, a new peak appeared at a retention time of $15.9 \mathrm{~min}$, indicating the formation of the cysteine adduct (Figure S4A). The peak was confirmed to be the cysteine adduct $(\mathrm{m} / \mathrm{z} 450$ $[\mathrm{M}+\mathrm{H}]^{+}$), a combination of the cysteine (MW 121) and biliatresone (MW 328) in the MS spectrum (Figure S4B). The LC analysis showed a decrease of the MeOH adduct ( $\mathrm{t}_{\mathrm{R}} 27.9$ min). The biliatresone peak diminished as a cysteine adduct formed; notably, in this instance, the $\mathrm{MeOH}$ adduct also decreased during the $18 \mathrm{~h}$ reaction. To remove the interference of the $\mathrm{MeOH}$ adduct, pure biliatresone was isolated, and a time-dependent reactivity toward cysteine was tested in an EtOH-based solvent. The formation of the cysteine adduct was completed within $10 \mathrm{~h}$ (reaction rate of $0.254 \times 10^{-6} \mathrm{~mol} \mathrm{~s}^{-1}$, three times slower than the reactivity in the $\mathrm{MeOH}-$ based solvent) (Figures $3 \mathrm{~B}$ and $\mathrm{C}$ and Table 1). The use of a nucleophilic solvent, such as $\mathrm{MeOH}$, markedly influenced the reactivity of biliatresone. The cysteine derivatives D-NAC and L-NAC also were tested; their reactivity was about 2-fold higher compared to that of cysteine in the MeOH-based solvent (Table 1 and Figure S5). The acetyl group of NAC is an electron withdrawing group (EWG) and contributes to an overall electron-deficient molecule, leading to its higher reactivity with biliatresone compared to that of cysteine.

The reactivities of biliatresone with various amino acids (histidine, glycine, glutamate, phenylalanine, and serine), all of which lack thiol groups, were tested with the same experimental design as that used for GSH. Analysis of the reactions established the reactivity in the order of histidine $\gg$ glycine $>$ glutamate $>$ phenylalanine and no reactivity with serine (Table 1 and Figure S6-S10A). A time-dependent analysis of the formation of the histidine adduct showed very strong reactivity within a short time of $10 \mathrm{~min}$. Structurereactivity analysis suggested that the imidazole moiety of histidine contributed to the higher 
reactivity (Figure 1). This observation led us to consider whether DNA and RNA could be targets for binding of biliatresone since adenine and guanine also contain imidazole rings. Therefore, we tested the reactivity of biliatresone with the nucleic acid base adenine, but we observed no conjugation (Figure S10B). The imidazole ring of adenine is fused to a pyrimidine. We then focused on the free imidazole ring of histamine for the reactivity with biliatresone. The histamine adduct of biliatresone was detected and formed at a 3-fold slower rate than the reactivity toward histidine (Figure S11). These data suggest that the reactivity of biliatresone to the imidazole ring is specific to histidine and histamine. These data suggest that histidine and histamine are likely targets of biliatresone in vivo.

Conjugation of ethyl vinyl ketone (EVK, 1-penten-3-one) toward GSH was measured in our HPLC-based analysis with similar experimental conditions as those used for biliatresone and was compared to the conjugation rate of biliatresone with GSH. The formation of the EVK adduct of GSH was completed within $11 \mathrm{~h}$ with a reaction rate of $\sim 0.076 \times 10^{-6} \mathrm{~mol} \mathrm{~s}^{-1}$ (Table 1 and Figure S12). The reactivity of EVK was around 10-fold weaker than the reactivity of biliatresone, suggesting that biliatresone is highly reactive compared to the electrophile EVK in our HPLC assay.

Kinetic studies to determine second-order rate constants $(k)$ of the conjugations of biliatresone, DP, and EVK toward GSH were performed under nonstoichiometric ratio conditions. Second-order reaction rate constant was determined employing first-order with respect to both reactant $[\mathrm{A}]_{0}$ and GSH $[\mathrm{GSH}]_{0}$. The value of $[\mathrm{A}]_{\mathrm{t}}$ was obtained by measuring decreased peak area of the reactant for a given time $t$ in the HPLC spectrum. Least squares plots of $\ln \left([\mathrm{A}]_{\mathrm{t}} /[\mathrm{GSH}]_{\mathrm{t}}\right)$ vs $t$ gave straight lines with slope $\left([\mathrm{A}]_{0}-[\mathrm{GSH}]_{0}\right) k$ and regression coefficient $R^{2}$ (Figure S13). The relative reaction rate constants for comparison to biliatresone were obtained by dividing the rate constant of biliatresone into each rate constant of the other two reactions (Table 2). The reaction rate constants $k$ of biliatresone, DP, and EVK were $0.1254,0.0121$, and $0.0191 \mathrm{M}^{-1} \mathrm{~s}^{-1}$. The relative reaction rate constants of DP and EVK with GSH were about 10-fold and 6.7-fold weaker than the rate constant for biliatresone in reaction with GSH. The comparative results of DP and biliatresone in reaction with GSH demonstrate the importance of the functional groups of biliatresone in the reactivity.

\section{DISCUSSION}

Biliatresone behaves as a strong electrophile that participates in addition reactions toward the nucleophiles GSH, NAC, cysteine, histidine, and histamine in our assay system. We analyzed the reactivity of biliatresone and determined the occurrence of electrophilic addition reactions with the biomolecular nucleophiles through the use of HPLC and LC-MS analyses. The long-term reaction of the GSH adduct with the $\mathrm{MeOH}$ adduct of biliatresone after the removal of biliatresone from the solution by reactivity with GSH showed that the $\mathrm{MeOH}$ adduct participated in a reverse Michael reaction (retro-Michael) (Figure 2B). The retro-Michael reaction is known to occur readily under biological conditions as well as in the reversible reaction of GSH conjugation. ${ }^{12,13}$ Electrophiles with Michael acceptors, such as $a, \beta$-unsaturated ketones and aldehydes, form the retro-Michael addition product at high concentrations. ${ }^{14}$ The core structure of the Michael acceptor in the adduction reaction and 
presumably in the biological toxicity is the $a$-methylene ketone of the 1,2-diaryl-2propenone, with the $a$-methylene ketone between the two phenyls and lacking the other functional groups of biliatresone. Compounds that contain the $\alpha$-methylene ketone are a subset of the $\alpha, \beta$-unsaturated carbonyl compounds; there are a limited number of reports in which the activities of the $\alpha$-methylene ketones are investigated. ${ }^{5,15-18}$ Studies of $\alpha, \beta$ unsaturated carbonyl compounds can provide useful concepts for an understanding of the reactivity of biliatresone. The biological activities of the compounds that contain the $a$ methylene ketone have been demonstrated in studies of the natural electrophiles helenalin (target: NF- $k \mathrm{~B}$ ), ethacrynic acid (target: cysteine of glutathione S-transferase P1-1), parthenolide (target: $\mathrm{I} k \mathrm{~B}$ ), 4-isoavenaciolide (target: VHR phosphatase), and the microcystins (target: cys273 of serine/threonine phosphatase), as well as in the synthetic electrophiles 2-crotonyoxymethyl-2-cycloalkenone (target: glutathione-S-transferase), and 15-methylene-eburnamonine (target: unspecified thiols). ${ }^{19-25}$ To investigate the reactive compounds, the chemical reactivity toward GSH and the screening of DNA-reactive mutagenicity with 4-(4-nitrobenzyl)pyridine of $\alpha, \beta$-unsaturated carbonyl compounds and various other organic electrophiles were previously evaluated in a chemoassay design with UV-vis spectrometry assessment of reaction kinetics. ${ }^{9,10,26}$ In this study, a 96-well microtiter plate-based screening system was used in a thiol reactivity screen for a simple and quick determination of binding to cysteamine, dithiothreitol, 2-mercaptoethanol, GSH, and cysteine. ${ }^{27}$ These reports led us to examine the reactivity of biliatresone toward EVK, one of the more reactive compounds studied.

The histidine conjugation of biliatresone was rapid compared to the reaction with the thiol ($\mathrm{SH})$ groups of GSH, NAC, and cysteine. Comparison of the $\mathrm{pK}_{\mathrm{a}}$ values for these compounds was not a definitive measure of the reactivities achieved in our assay. Serine was expected to have relatively high reactivity because of its high $\mathrm{pK}_{\mathrm{a}}$, but it was not reactive. This could be due to reduced nucleophilicity through intramolecular hydrogen bonding in protic solvents, water, and $\mathrm{MeOH} .{ }^{28}$ These results could suggest that the $\alpha$-methylene ketone is more specifically reactive toward a nucleophile that contains the $\mathrm{N}$ atom with a lone pair of electrons, as in imidazole; however, the reaction with adenine failed. This also may be due to intramolecular hydrogen bonding interactions, although the known and likely intramolecular hydrogen bonds of adenine do not explain the lack of reactivity toward the imidazole $\mathrm{N}$ of adenine. ${ }^{9}$ The deoxyguanosine and guanine adducts were isolated and studied in the reaction of EVK in the SOS Chromotest for genotoxicity evaluation, suggesting that the guanine moiety of DNA is a more reactive constituent than adenine. ${ }^{29}$ However, these ideas need further exploration since the conjugation reactions of free nucleic acids and the three-dimensional DNA double helix are likely to be different.

An example of histidine conjugation similar to that exhibited by biliatresone occurs with acrolein, an environmental pollutant with a terminal methylene ketone generated during lipid peroxidation; acrolein interacts with protein through conjugation with histidine. ${ }^{30}$ Although the reactivities of the free amino acids are not indicative of their reactivities in a protein, our results suggest the possibility that biliatresone may interact directly with proteins, through thiol and imidazole groups, to cause changes in protein activation, structure, or folding. 
While we regard the synthetic DP as the essential structure of the toxic core moiety, we have yet to identify the particular biological target at the molecular level. When DP was tested against GSH, a GSH adduct formed, although at a 10-fold slower rate than that of biliatresone. The time-dependent analysis of the GSH adduct with biliatresone showed a reaction rate of $\sim 0.754 \times 10^{-6} \mathrm{~mol} \mathrm{~s}^{-1}$, while synthetic DP also formed a GSH adduct but with a reaction rate of $\sim 0.075 \times 10^{-6} \mathrm{~mol} \mathrm{~s}^{-1}$ (Table 1 and Figure 4), suggesting that the methylenedioxy, dimethoxyl, and hydroxyl functional groups of biliatresone contributed to its hard electrophilic nature. Previous studies showed an enhanced Michael addition reaction rate toward GSH in the presence of a phenyl with an ortho-hydroxyl group, such as is found in biliatresone. ${ }^{31}$

To compare the reactive potency in our HPLC assay of a representative $\alpha, \beta$-unsaturated carbonyl compound that lacks a phenyl group, we investigated the kinetics of the GSH conjugation with EVK, which is a gaseous irritant with toxicity to the upper respiratory tract that acts as a toxic alkylating agent with a mutagenic and carcinogenic risk. ${ }^{5,32,33} \mathrm{EVK}$ was the most highly reactive of the compounds studied in the GSH kinetic chemoassay reported previously. ${ }^{9,10}$ In our HPLC assay, the EVK adduct of GSH formed at a similar reaction rate as observed for the reaction of synthetic DP with GSH, while the EVK adduct was 1.5-fold higher in the reaction rate constant analysis (Tables 1 and 2). The reaction rate constants again confirmed that the reactivity of bilitresone is higher by about 10-fold and 6.7-fold compared to that of the synthetic DP and EVK, respectively (Table 2). Collectively, our studies highlight the importance of the functional groups on the two phenyls of biliatresone in its electrophilic reactivity; the synthetic DP was nearly equal in potency as an electrophile as EVK. The methylenedioxy, dimethoxyl, and hydroxyl functional groups are all electron donating groups (EDG). The Michael acceptor $a$-methylene ketone is a center of low electron density as an EWG that can accept an electron pair to form a covalent bond, exhibiting the reactivity spontaneously with the nucleophilic site of the biomolecules. ${ }^{34}$ Similarly, hydroxyl chalcones have both EWG and EDG; chalcones with an ortho-hydroxyl in the phenyl ring $\beta$ to the ketone and dihydroxychalcones with hydroxyl groups $\beta$ and $\delta$ to the ketone highly deplete intracellular glutathione. ${ }^{27,35}$ Dimethoxyl groups may have a similar potentiating effect. The $2^{\prime}-\mathrm{OH}$ ( $\gamma$ to the ketone) and $6-\mathrm{OCH}_{3}$ ( $\beta$ to the ketone) of biliatresone have similar relative positions and can be expected to similarly increase reactivity. The reaction with dual EDG and EWG activation by nucleophilic attack may lead to a rapid reaction rate. The strong reactivity of biliatresone is a consequence of the enhanced electrophilicity.

Solvolysis can have a confounding effect on the determination of reactivity and reaction rate kinetics. ${ }^{26}$ We have conducted many quantitative HPLC and NMR studies of biliatresone in $\mathrm{MeOH} /$ water, $\mathrm{EtOH} /$ water, $\mathrm{MeCl}_{2}$, and $\mathrm{CHCl}_{3}$ solvents over periods of several years. Although adduct formation with water and $\mathrm{MeOH}$ have been seen, as mentioned, we have not seen any evidence of solvolysis of biliatresone in these studies.

In summary, we have characterized the reactivity of biliatresone to identify possible mechanisms that underlie its extrahepatic biliary toxicity. The $a$-methylene ketone of biliatresone readily reacts with thiols of GSH and cysteine and the free imidazole of histidine and histamine. The identification of proteins in the biliary endothelium with 
cysteine and histidine-rich domains may lead us to targets that explain the specificity of the toxicity. In the case of the natural toxin microcystin-LR, which is directly involved in hepatic toxicity but does not cause biliary atresia, the binding of the $a$-methylene to the cys 273 residue in the serine/threonine phosphatase perturbs activity through proximity to residue tyr272, involved in enzyme catalytic metal binding and occupation of a surface groove involved in substrate binding; this latter interaction accounts for enzyme inhibition, even when the cys 273 is mutated. ${ }^{23}$ Reduction of a microcystin to its dihydromicrocystin abolished the ability of the toxin to form covalent bonds with the enzyme, suggesting the importance of the Michael addition of the $\alpha$-methylene and cysteine residue in protein activation and toxicity. ${ }^{36,37}$ Understanding the reactivity of biliatresone may enable us to identify similar molecules with relevance to human biliary atresia.

\section{Supplementary Material}

Refer to Web version on PubMed Central for supplementary material.

\section{ACKNOWLEDGMENTS}

We thank Cristina Tettamanzi de Sproveiro for assistance with the NMR studies and Rodney J. Wigent for assistance with the kinetic analysis.

Funding

This work was supported by grants from the NIDDK (R01-DK-092111), the Commonwealth of Pennsylvania (KIZ KISK C000043713), the Fred and Suzanne Biesecker Center for Pediatric Liver Diseases at The Children's Hospital of Philadelphia, the College of Graduate Studies at the University of the Sciences in Philadelphia, and a pilot grant from the University of Pennsylvania NIDDK Center for Molecular Studies of Digestive and Liver Diseases (P30-DK-05036).

\section{ABBREVIATIONS}

$\begin{array}{ll}\text { ACN } & \text { acetonitrile } \\ \text { CHCl }_{3} & \text { chloroform } \\ \text { DAD } & \text { diode array detector } \\ \text { DP } & \text { 1,2-diaryl-2-propen-1-one } \\ \text { EDG } & \text { electron donating group } \\ \text { ESI } & \text { electrospray ionization } \\ \text { EtOH } & \text { ethanol } \\ \text { EVK } & \text { ethyl vinyl ketone } \\ \text { EWG } & \text { electron withdrawing group } \\ \text { GSH } & \text { glutathione } \\ \text { HMBC } & \text { heteronuclear multiple bond correlation spectroscopy } \\ \text { HPLC } & \text { high-performance liquid chromatography } \\ \text { LC-MS } & \text { liquid chromatography-mass spectrometry }\end{array}$




$\begin{array}{ll}\mathbf{M e C l}_{2} & \text { methylene chloride } \\ \mathbf{M e O H} & \text { methanol } \\ \mathbf{M W} & \text { molecular weight } \\ \mathbf{N A C} & N \text {-acetyl-cysteine } \\ \mathbf{N M R} & \text { nuclear magnetic resonance } \\ \mathbf{t}_{\mathbf{R}} & \text { retention time } \\ \mathbf{V H R} & \text { VH1-related }\end{array}$

\section{REFERENCES}

(1). Lorent K, Gong W, Koo KA, Waisbourd-Zinman O, Karjoo S, Zhao X, Sealy I, Kettleborough RN, Stemple DL, Windsor PA, Whittaker SJ, Porter JR, Wells RG, Pack M. Identification of a plant isoflavonoid that causes biliary atresia. Sci. Transl. Med. 2015; 7:286ra67.

(2). Koo KA, Lorent K, Gong W, Windsor P, Whittaker SJ, Pack M, Wells RG, Porter JR. Biliatresone, a reactive natural toxin from Dysphania glomulifera and D. littoralis: discovery of the toxic moiety 1,2-diaryl-2-propenone. Chem. Res. Toxicol. 2015; 28:1519-1521. [PubMed: 26175131]

(3). Kelly GE, Nelson C, Waring MA, Joannou GE, Reeder AY. Metabolites of dietary (soya) isoflavones in human urine. Clin. Chim. Acta. 1993; 223:9-22. [PubMed: 8143372]

(4). Umezawa T, Nakatsubo F, Higuchi T. Lignin degradation by Phanerochaete chrysosporium: metabolism of a phenolic phenylcoumaran substructure model compound. Arch. Microbiol. 1982; 131:124-128.

(5). Koleva YK, Madden JC, Cronin MTD. Formation of categories from structure-activity relationships to allow read-across for risk assessment: toxicity of $\alpha, \beta$-unsaturated carbonyl compounds. Chem. Res. Toxicol. 2008; 21:2300-2312. [PubMed: 19053326]

(6). Jian W, Lee SH, Mesaros C, Oe T, Elipe MV, Blair IA. A novel 4-oxo-2(E)-nonenal-derived endogenous thiadiazabicyclo glutathione adduct formed during cellular oxidative stress. Chem. Res. Toxicol. 2007; 20:1008-1018. [PubMed: 17550273]

(7). Barshteyn N, Elfarra AA. Formation of mono- and bis-Michael adducts by the reaction of nucleophilic amino acids with hydroxymethylvinyl ketone, a reactive metabolite of 1,3butadiene. Chem. Res. Toxicol. 2009; 22:918-925. [PubMed: 19317513]

(8). Antunes AM, Godinho AL, Martins IL, Justino GC, Beland FA, Marques MM. Amino acid adduct formation by the nevirapine metabolite, 12-hydroxynevirapine - a possible factor in nevirapine toxicity. Chem. Res. Toxicol. 2010; 23:888-899. [PubMed: 20392079]

(9). Böhme A, Thaens D, Paschke A, Schüürmann G. Kinetic glutathione chemoassay to quantify thiol reactivity of organic electrophiles-application to $\alpha, \beta$-unsaturated ketones, acrylates, and propiolates. Chem. Res. Toxicol. 2009; 22:742-750. [PubMed: 19317512]

(10). Böhme A, Thaens D, Schramm F, Paschke A, Schüürmann G. Thiol reactivity and its impact on the ciliate toxicity of $a, \beta$-unsaturated aldehydes, ketones, and esters. Chem. Res. Toxicol. 2010; 23:1905-1912. [PubMed: 20923215]

(11). Reynolds, WF.; Mozzola, EP. Nuclear Magnetic Resonance in the Structure Elucidation of Natural Products. In: Kinghorn, AD.; Falk, H.; Kobayashi, J., editors. Progress in the Chemistry of Organic Natural Products 100. Springer International Publishing; Cham, Switzerland: 2015. p. 234

(12). Shabat D, Rader C, List B, Lerner RA, Barbas CF. Multiple event activation of a generic prodrug trigger by antibody catalysis. Proc. Natl. Acad. Sci. U. S. A. 1999; 96:6925-6930. [PubMed: 10359815]

(13). Shi B, Greaney MF. Reversible Michael addition of thiols as a new tool for dynamic combinatorial chemistry. Chem. Commun. 2005; 7:886-888. 
(14). Monks TJ, Anders MW, Dekant W, Stevens JL, Lau SS, van Bladeren PJ. Glutathione conjugate mediated toxicities. Toxicol. Appl. Pharmacol. 1990; 106:1-19. [PubMed: 2251674]

(15). Woods JR, Mo H, Bieberich AA, Alavanja T, Colby DA. Fluorinated amino-derivatives of the sesquiterpene lactone, parthenolide, as ${ }^{19} \mathrm{~F}$ NMR probes in deuterium-free environments. J. Med. Chem. 2011; 54:7934-7941. [PubMed: 22029741]

(16). Yasuo T, Tadanobu I. Inhibition of human hepatic glutathione S-transferase isozymes by ethacrynic acid and its metabolites. Toxicol. Lett. 1992; 62:241-245. [PubMed: 1412509]

(17). Schmidt TJ. Glutathione adducts of helenalin and 11 alpha, 13-dihydrohelenalin acetate inhibit glutathione S-transferase from horse liver. Planta Med. 2000; 66:106-109. [PubMed: 10763580]

(18). Skalska J, Brookes PS, Nadtochiy SM, Hilchey SP, Jordan CT, Guzman ML, Maggirwar SB, Briehl MM, Bernstein SH. Modulation of cell surface protein free thiols: a potential novel mechanism of action of the sesquiterpene lactone parthenolide. PLoS One. 2009; 4:e8115. [PubMed: 19956548]

(19). Schmidt TJ. Helenanolide-type sesquiterpene lactones-III. Rates and stereochemistry in the reaction of helenalin and related helenanolides with sulfhydryl containing biomolecules. Bioorg. Med. Chem. 1997; 5:645-653. [PubMed: 9158862]

(20). Ploemen JH, van Schanke A, van Ommen B, van Bladeren PJ. Reversible conjugation of ethacrynic acid with glutathione and human glutathione S-transferase P1-1. Cancer Res. 1994; 54:915-919. [PubMed: 8313381]

(21). Kwok BH, Koh B, Ndubuisi MI, Elofsson M, Crews CM. The anti-inflammatory natural product parthenolide from the medicinal herb feverfew directly binds to and inhibits $\mathrm{I} k \mathrm{~B}$ kinase. Chem. Biol. 2001; 8:759-766. [PubMed: 11514225]

(22). Ueda K, Usui T, Nakayama H, Ueki M, Takio K, Ubukata M, Osada H. 4-Isoavenaciolide covalently binds and inhibits VHR, a dual-specificity phosphatase. FEBS Lett. 2002; 525:48-52. [PubMed: 12163160]

(23). Goldberg J, Huang HB, Kwon YG, Greengard P, Nairn AC, Kuriyan J. Three-dimensional structure of the catalytic subunit of protein serine/threonine phosphatase-1. Nature. 1995; 376:745-753. [PubMed: 7651533]

(24). Hamilton DS, Zhang X, Ding Z, Hubatsch I, Mannervik B, Houk KN, Ganem B, Creighton DJ. Mechanism of the glutathione transferase-catalyzed conversion of antitumor 2crotonyloxymethyl-2-cycloalkenones to GSH adducts. J. Am. Chem. Soc. 2003; 125:1504915058. [PubMed: 14653739]

(25). Woods JR, Riofski MV, Zheng MM, O'Banion MA, Mo H, Kirshner J, Colby DA. Synthesis of 15-methylene-eburnamonine from (+)-vincamine, evaluation of anticancer activity, and investigation of mechanism of action by quantitative NMR. Bioorg. Med. Chem. Lett. 2013; 23:5865-5869. [PubMed: 24055047]

(26). Thaens D, Heinzelmann D, Böhme A, Paschke A, Schüürmann G. Chemoassay screening of DNA-reactive mutagenicity with 4-(4-nitrobenzyl)pyridine-application to epoxides, oxetanes, and sulfur heterocycles. Chem. Res. Toxicol. 2012; 25:2092-2102. [PubMed: 22889134]

(27). Amslinger S, Al-Rifai N, Winter K, Wörmann K, Scholz R, Baumeister P, Wild M. Reactivity assessment of chalcones by a kinetic thiol assay. Org. Biomol. Chem. 2013; 11:549-554. [PubMed: 23224077]

(28). Nagy PI. Competing intramolecular vs. intermolecular hydrogen bonds in solution. Int. J. Mol. Sci. 2014; 15:19562-19633. [PubMed: 25353178]

(29). Eder E, Hoffman C, Deininger C. Identification and characterization of deoxyguanosine adducts of methyl vinyl ketone and ethyl vinyl ketone. Genotoxicity of the ketones in the SOS Chromotest. Chem. Res. Toxicol. 1991; 4:50-57. [PubMed: 1912300]

(30). Maeshima T, Honda K, Chikazawa M, Shibata T, Kawai Y, Akagawa M, Uchida K. Quantitative analysis of acrolein-specific adducts generated during lipid peroxidation-modification of proteins in vitro: Identification of $\mathrm{N}^{\tau}$-(3-propanal)histidine as the major adduct. Chem. Res. Toxicol. 2012; 25:1384-1392. [PubMed: 22716039]

(31). Ha H-J, Yoon D-H, Park S, Kim H-J. Fluorescence turn-on probe for biothiols: intramolecular hydrogen bonding effect on the Michael reaction. Tetrahedron. 2011; 67:7759-7762. 
(32). Morgan DL, Ward SM, Wilson RE, Price HC, O’Connor RW, Seely JC, Cunningham ML. Inhalation toxicity studies of the alpha,beta-unsaturated ketones: ethyl vinyl ketone. Inhalation Toxicol. 2001; 13:633-658.

(33). Deininger C, Eder E, Neudecker T, Hoffman C. Mutagenicity and genotoxicity of ethylvinyl ketone in bacterial tests. J. Appl. Toxicol. 1990; 10:167-171. [PubMed: 2199554]

(34). Coleman JOD, Blake-Kalff MMA, Davies ETG. Detoxification of xenobiotics by plants: chemical modification and vacuolar compartmentation. Trends Plant Sci. 1997; 2:144-151.

(35). Kachadourian R, Day BJ. Flavonoid-induced glutathione depletion: potential implications for cancer treatment. Free Radical Biol. Med. 2006; 41:65-76. [PubMed: 16781454]

(36). Craig M, Luu HA, McCready TL, Williams D, Andersen RJ, Holmes CF. Molecular mechanisms underlying the interaction of motuporin and microcystins with type-1 and type-2A protein phosphatases. Biochem. Cell Biol. 1996; 74:569-578. [PubMed: 8960363]

(37). Pereira SR, Vasconcelos VM, Antunes A. Computational study of the covalent bonding of microcystins to cysteine residues-a reaction involved in the inhibition of the PPP family of protein phosphatases. FEBS J. 2013; 280:674-680. [PubMed: 22177231] 
<smiles>C=C(C(=O)c1c(OC)cc2c(c1OC)OCO2)c1ccccc1O</smiles>

Biliatresone<smiles>C=C(C(=O)c1ccccc1)c1ccccc1</smiles>

1,2-Diaryl-2-propen-1-one<smiles>C=CC(=O)CC</smiles>

Ethyl vinyl ketone<smiles>NC(CCC(=O)O)C(=O)O</smiles><smiles>NCC(=O)O</smiles>

Glutamate

Glycine<smiles>NC(CS)C(=O)O</smiles><smiles>O=C(I)N[C@@H](CS)C(=O)O</smiles>

$\mathrm{N}$-acetyl-D-cysteine<smiles>CC(=O)N[C@@H](CS)C(=O)O</smiles>

$\mathrm{N}$-acetyl-L-cysteine<smiles>NC(Cc1ccccc1)C(=O)O</smiles><smiles>NC(CO)C(=O)O</smiles>

Serine<smiles>NC(Cc1c[nH]cn1)C(=O)O</smiles>

Histidine

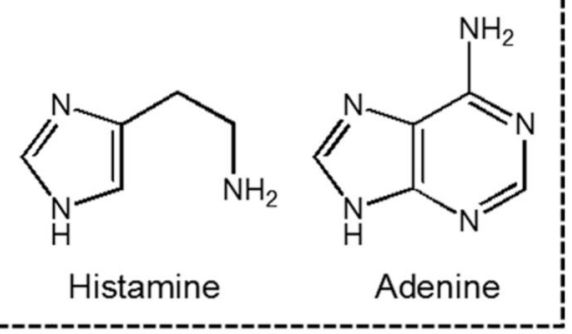<smiles>[R][X]1=C=CC=C(C(=C)C(=O)c2ccccc2)C=C1</smiles><smiles>[R3][C]1CC1</smiles>
Michael addition<smiles>[R]NCC(C(=O)C1=CC=C[I-]([R])=C1)c1ccccc1</smiles>

Figure 1.

Chemical structures of biliatresone, DP, EVK, the amino acids, and thiol- or imidazolecontaining molecules (dashed box) tested in this study. 
A. Short-term reaction

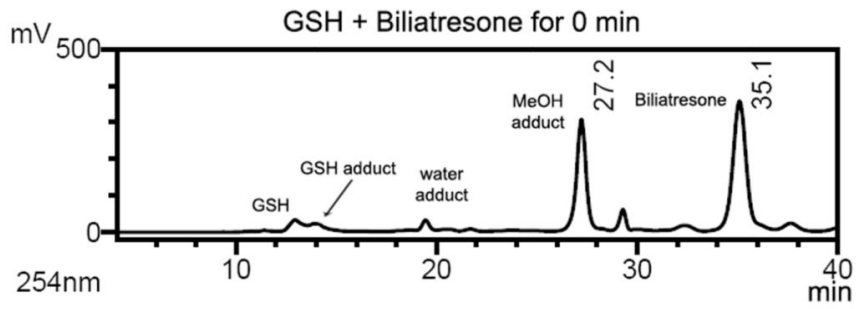

GSH + Biliatresone for $5 \mathrm{~min}$
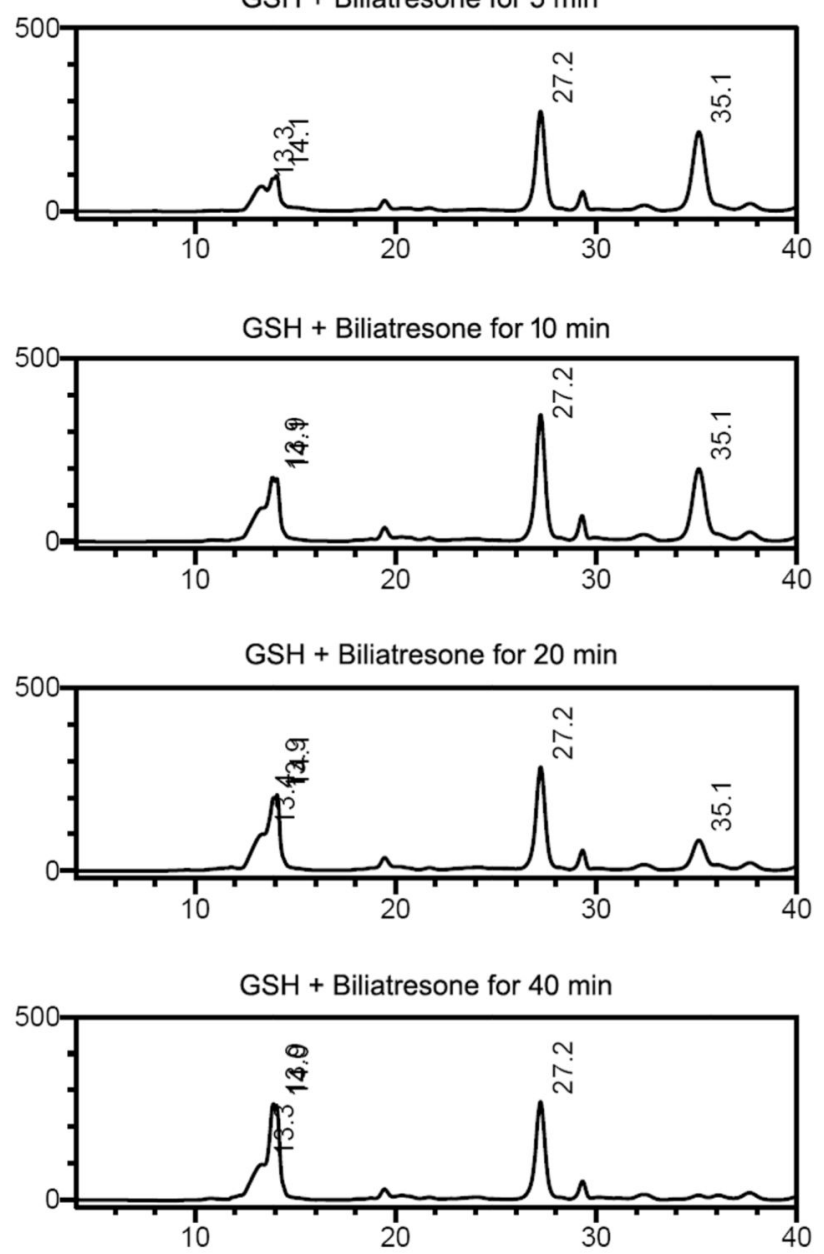

\section{B. Long-term reaction}
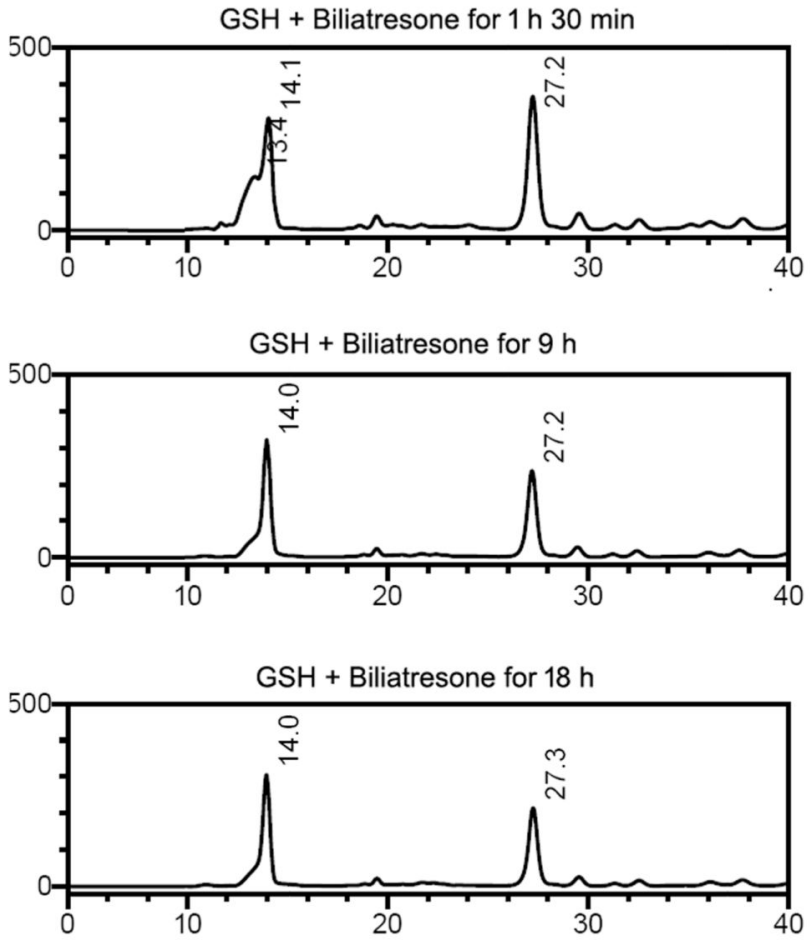

C.

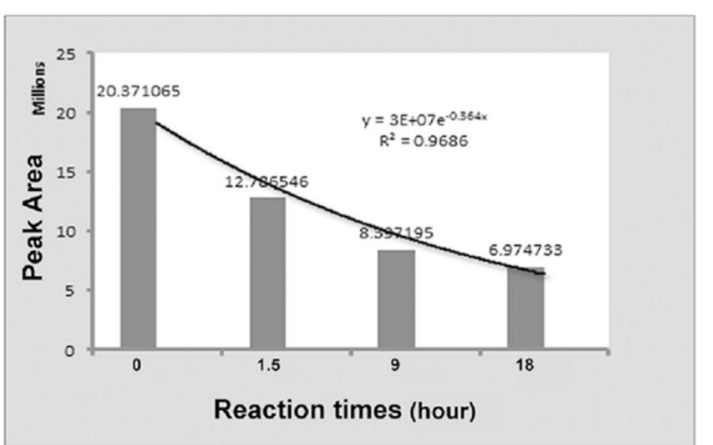

Figure 2.

LC-MS analysis of the time-dependent conjugation of GSH and biliatresone in a short-term reaction (A) for $40 \mathrm{~min}$ and a long-term reaction (B) for $18 \mathrm{~h}$. LC chromatograms were monitored at $254 \mathrm{~nm}$ to maximize the intensity of the GSH-biliatresone adduct peak relative to the height of GSH. The area of the peak of the $\mathrm{MeOH}$ adduct decreased slightly during the reaction. (C) Time course of variation on the peak areas of the $\mathrm{MeOH}$ adduct in the reaction. The line is an exponential best-fit line of the peak areas vs. the reaction times. 


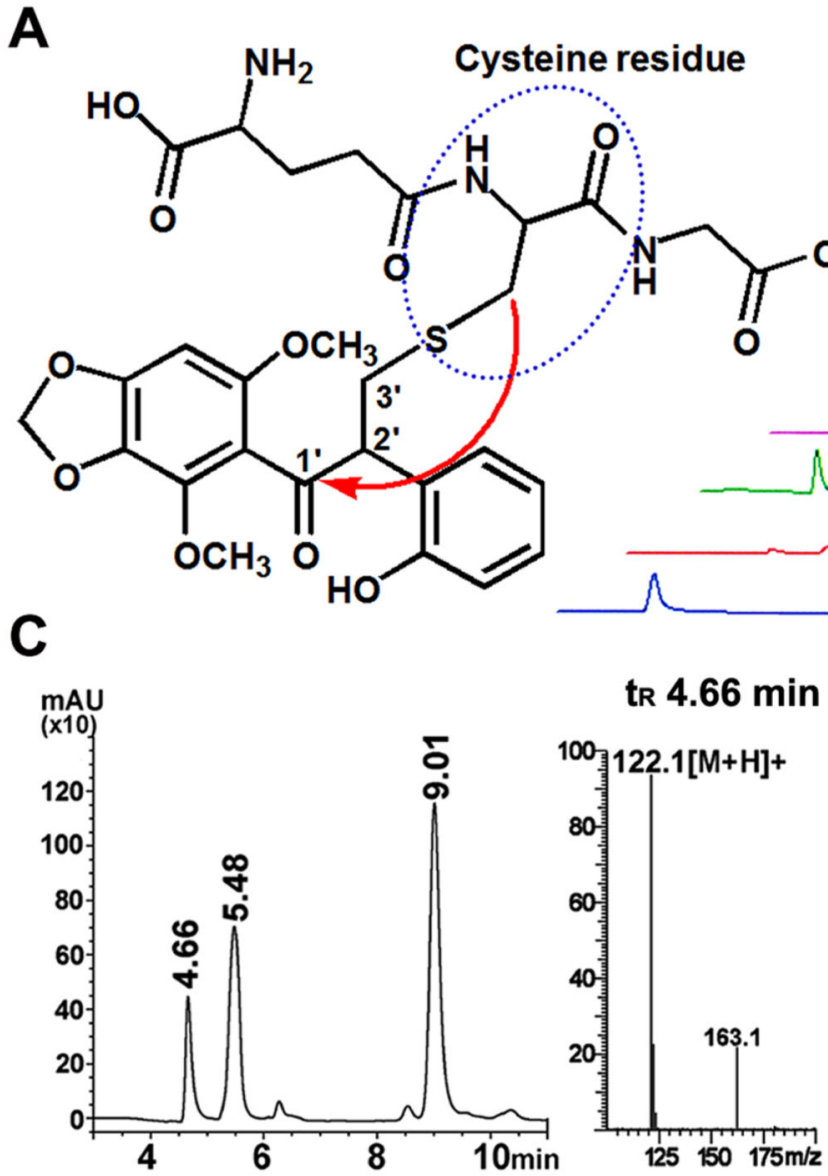

B

C
$t_{R} \mathbf{5 . 4 8} \mathrm{min}$

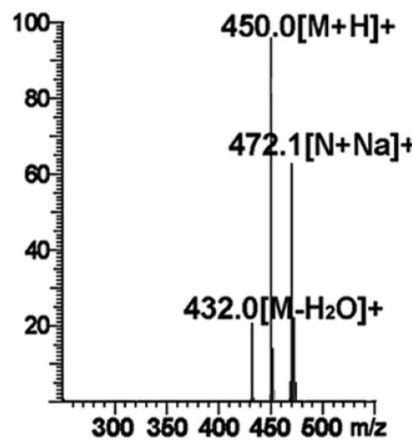

Cysteine adduct

Figure 3.

2D NMR HMBC and LC-MS analyses of GSH and cysteine conjugation to biliatresone. (A) The GSH adduct of biliatresone occurs at the thiol $(-\mathrm{SH})$ of the cysteine residue (blue circle) by oxidative cleavage of the $a$-methylene ( $3^{\prime}$ position) in biliatresone. The red arrow indicates a significant long-range $\mathrm{HMBC}$ correlation in the conjugation product. (B) 3D time-course representation of the formation of the cysteine adduct of biliatresone in the EtOH-based solvent; each HPLC trace was taken at the time intervals shown and compared to the chromatograms of cysteine and biliatresone alone. (C) MS analysis of the peaks shown in the HPLC chromatogram (cysteine $t_{R} 4.66$ min; cysteine adduct $t_{R} 5.48$ min; biliatresone $t_{R} 9.01 \mathrm{~min}$ ) of the reaction after a $2 \mathrm{~h}$ incubation from the experiment shown in (B). 

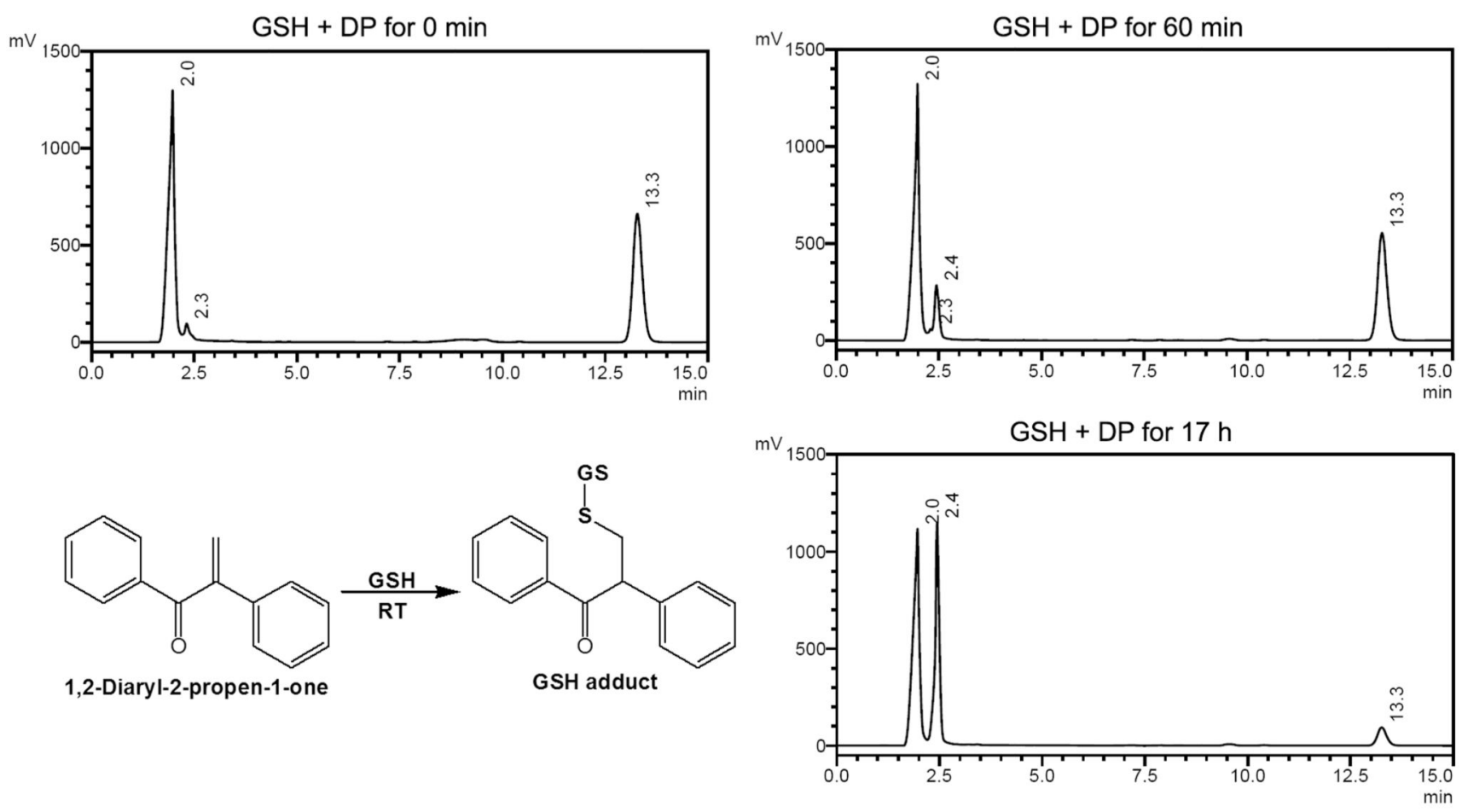

Figure 4.

HPLC analysis of the time-dependent conjugation of GSH and the synthetic 1,2-diaryl-2propen-1-one (DP) for $18 \mathrm{~h}$ at $206 \mathrm{~nm}$, flow rate $0.5 \mathrm{~mL} / \mathrm{min}$; GSH ( $\mathrm{t}_{\mathrm{R}} 2.0 \mathrm{~min}$ ), GSH adduct $\left(\mathrm{t}_{\mathrm{R}} 2.3-2.4 \mathrm{~min}\right)$ and $\mathrm{DP}\left(\mathrm{t}_{\mathrm{R}} 13.3 \mathrm{~min}\right)$. 
Table 1

Reactivities of Biliatresone toward Biomolecules and the Reactivities of DP and EVK

toward $\mathrm{GSH}^{a}$

\begin{tabular}{llll}
\hline \multicolumn{1}{c}{ Test samples } & $\begin{array}{c}\text { Reaction Rate } \\
\mathbf{m o l ~ s}^{-1}\left(\times \mathbf{~ 1 0}^{-6}\right)\end{array}$ & Test samples & $\begin{array}{c}\text { Reaction Rate } \\
\mathbf{m o l ~ s}^{-1}\left(\times \mathbf{~ 1 0}^{-6}\right)\end{array}$ \\
\hline \multirow{2}{*}{ GSH Biliatresone } & 0.754 & Glycine & 0.024 \\
$\quad$ DP & 0.075 & Phenylalanine & 0.005 \\
\multicolumn{1}{c}{ EVK } & 0.076 & Serine & $<0.001$ \\
Cysteine & 0.721 & Histidine & 2.877 \\
D-NAC / L-NAC & 1.667 & Histamine & 0.833 \\
Glutamate & 0.011 & Adenine & $<0.001$ \\
\hline
\end{tabular}

$a_{\text {The dashed box is the reactivity toward GSH. }}$ 
Table 2

Second-Order Reaction Rate Constants of the Reactivities of Biliatresone, DP, and EVK toward GSH

\begin{tabular}{llll}
\hline & biliatresone & DP & EVK \\
\hline reaction rate constant $k\left(\mathrm{M}^{-1} \mathrm{~s}^{-1}\right)$ & 0.1254 & 0.0121 & 0.0191 \\
regression coefficient $R^{2}$ & 0.9948 & 0.9998 & 0.9903 \\
reaction rate relative to biliatresone & 1 & 0.10 & 0.15
\end{tabular}

